CHECCHI GONZÁLEZ, Tania Universidad Iberoamericana de Mexico

@ taniachecchi@icloud.com

\title{
El tiempo, los cainitas y Babel: una lectura a partir de René Girard y Emmanuel Lévinas
}

\author{
The time, the cainitas and Babel: a reading \\ from René Girard and Emmanuel Lévinas
}

\begin{abstract}
A contracorriente de ciertas interpretaciones que encuentran en el episodio bíblico de Babel una terrible y por demás inmerecida sanción divina, diversos autores de filiación judeocristiana han leído este brevísimo relato como una denuncia de los afanes totalitarios. Justamente en esta estela se inserta la acerada crítica que contra la mentalidad mítica erigen tanto Emmanuel Levinas como René Girard, para leer este episodio fascinante como una prolongación más de lo que podríamos designar como políticas cainitas.
\end{abstract}

PALABRAS CLAVE: Biblia, Babel, totalitarismo.

Contrary to certain interpretations that find in the biblical episode of Babel a terrible and undeserved other divine sanction, several authors of Judeo-Christian affiliation have read this brief story as a denunciation of totalitarian zeal. Precisely in this stele is inserted the steely criticism that against the mythical mentality erect both Emmanuel Levinas and René Girard, to read this fascinating episode as a prolongation more than what we could designate as Cainite policies.

KEY WORDS: Bible, Babel, totalitarianism.

A contracorriente de ciertas interpretaciones, muy populares aún hoy, que encuentran en el episodio bíblico de Babel una terrible y por demás inmerecida sanción divina, ${ }^{[1]}$ diversos autores de filiación judeocristiana han leído este brevísimo relato como una denuncia de los afanes totalitarios que ya desde tiempos arcaicos ha criticado duramente la tradición monoteísta. Y es que si, como bien dice Andre Neher, el monoteísmo profético es en esencia un monoteísmo ético, el espíritu de la profecía nada tiene que ver con dilucidar un futuro misterioso u oculto, sino con una denuncia infatigable del statu quo a partir del absoluto. Justamente en esta estela se inserta la acerada crítica que, contra la mentalidad mítica, erigen tanto Emmanuel Levinas como René Girard, crítica que nos provee de un hilo conductor para leer este episodio fascinante -y lo calificamos así a sabiendas de los riesgos que esto entraña- 
como una prolongación más de lo que podríamos designar -e intentaremos brevemente justificarlo- como políticas cainitas. En este respecto y de acuerdo con la secularización política dominante en nuestros días podríamos preguntarnos por qué valdría la pena volver hoy sobre este, tan manido, episodio. Entre otras razones, porque si, como lo señala André LaCocque -a quien seguiremos muy de cerca en nuestra lectura-, la protohistoria del redactor yahvista de la Biblia nos ofrece un retrato de la «condición universal que para siempre permea la existencia humana», ${ }^{[2]}$ el análisis de esta, en su estado perpetuo de crisis, se nos impone de manera apremiante al tiempo que se anticipa como interminable. Ahora bien, si en los primeros capítulos del Génesis el pensamiento bíblico nos presenta el quicio o articulación, entre la historia y la ontología, premisa que permite a Paul Ricoeur abordar el relato adámico ${ }^{[3]}$ y a LaCocque prolongar esa labor hasta Babel, trataremos en esta breve exposición de mostrar cómo este episodio nos alecciona, seres urbanos que mayoritariamente hoy somos, ${ }^{[4]}$ sobre las coordenadas básicas de nuestro habitar mundano en términos tanto temporales como éticos.

Ahora bien, si entre el relato del fraticidio de Caín y el episodio de Babel median sendas genealogías y la abrumadora descripción del diluvio, encontraríamos entre estas dos narraciones una lógica genética que tiene que ver con los inicios de lo urbano. Tras una angustiosa errancia, ambas ciudades -la erigida por Caín en Nod y la de los hombres emplazados en Shinar- son fundadas como fortificaciones contra esa misma ansiedad existencial y los rudimentos de lo instrumental llevados a su extrema sofisticación en la construcción de la torre ya están anunciados en los oficios a partir de los cuales se describe a los descendientes de Caín..$^{[5]}$ La urbe de Caín, además, según señala LaCocque, pretende sustituir los vínculos oríginales del primogénito de Adán y Eva, rotos irremisiblemente con la muerte de Abel, con una suerte de familia artificial, un colectivo que llevará el nombre de su hijo, Enoc. Pero lo que podría haber sido un nuevo inicio -Enoc significa 'inauguración'- termina en la genealogía cainita con el canto de Lamec, que se complace en su prepotente animosidad asesina. Significativamente, en esta misma tónica que vincula construcción y fraticidio, Michel Serrés, en su segundo volumen de las Fundaciones ${ }^{[6]}$ se pregunta por qué los hombres no vivimos simple y llanamente a cielo abierto, y responde: «Porque teníamos que estabilizar las piedras, esos proyectiles arrojadizos y letales, empezamos a construir; he ahí el origen de la arquitectura». .7] Así, la ciudad surgida del primer homicidio contiene la violencia en el doble sentido detectado por Girard y analizado por Dupuy: la detiene como un dique, pero la aloja en su interior. ${ }^{[8]}$ Se da entonces, como señala LaCocque, una suerte de reducción: los hombres, antes ciudadanos del mundo, en palabras de Filón, ${ }^{[9]}$ se convierten en la estela de Caín en seres urbanos cuya aglomeración acaba por «reducir el mundo a las proporciones de un universo construido a la medida humana y por producir, consecuentemente, una impresionante concentración de poder».[10]

Si estos son los antecedentes cainitas de lo urbano, encontraríamos su paroxismo en el puñado de versículos (Génesis 11:1-9) dedicados a Babel. En ellos, el redactor yahvista nos ofrece una descripción extremadamente condensada de lo que Levinas, a propósito de la religiosidad arcaica, llega a designar como estados de ánimo «prefascistas». ${ }^{[11]}$ Con una economía de lenguaje pasmosa, el autor bíblico logra crear una atmósfera que desde un inicio sugiere una suerte de saturación. Según LaCoque, la frase que abre este pasaje «Todo el mundo era de un mismo lenguaje e idénticas palabras» ${ }^{[12]}$ - «pocas palabras» en otras traducciones-implica que existía una gravísima limitación de intereses entre los hombres de Babel: 
solo contaba la construcción, de ahí sus gestos repetitivos, casi autísticos, esa exhortación referida a un nosotros monolingüe - «Vamos a edificarnos»-, sin un ellos, sin otredad alguna. Inmediatamente después, confirmando esta dinámica autorreferencial y obcecada, encontramos la siguiente frase que, en el francés de la traducción de Chouraqui, hace patente la recurrencia obsesiva de la actitud de los pobladores de Babel: «Allons, briquetons des briques, flambons-les à la flambée». ${ }^{[13]}$ Otras glosas nos han ahorrado, por afanes estilísticos, esta repetición, que, no obstante, tiene una poderosa razón de ser. Recordemos que Franz Rosenzweig, en su colaboración con Buber para la traducción de la Torá al alemán, insistía en conservar todas las repeticiones y presuntos pleonasmos del original con el fin de recuperar su potencia sugestiva y crítica. Las versiones que pulen o pretenden olvidar todas esas reiteraciones en pos de una mayor fluidez ocultan cómo estas llaman la atención sobre sí mismas convirtiéndose en el texto en admoniciones que no pueden ser obviadas, dada la extrema austeridad del lenguaje bíblico, tan admirado por Eric Auerbach. ${ }^{[14]}$ En suma, no se trata tan solo de la existencia de un solo lenguaje entre los hombres de Babel -tan añorado por algunos nostálgicos racionalistas-; el escritor yahvista recalca la monomanía de un colectivo que solo hablaba de las mismas cosas con las mismas palabras: debarim'ahadim.

Esta primera caracterización del clima de Babel nos permite establecer un contraste, subrayado también por LaCoque, entre el nosotros cerrado de la iniciativa de hombres de Babel -«vamos a edificarnos una ciudad» y «hagámonos famosos»- y el nosotros de Dios -«bajemos, pues»-, que señala, parodiándola, la ausencia en Babel de una auténtica comunicación, de ese cara a cara que según Levinas es el sine qua non de toda relación ética. ${ }^{[15]}$ Y si Dios desciende, como se atreve a afirmar el yahvista, no lo hace plegándose a la taumaturgia de los constructores, que buscan forzar una hierofanía, sino para corregir la asfixiante situación de una humanidad obstinada y preocupada tan solo por hacerse un nombre. Como señala Levinas en su texto Kenosis y judaísmo, cuando hablamos de Dios, su descenso y su elevación son inseparables, tal es el testimonio del tratado talmúdico Meguila 3: «Dondequiera que encontreis la potencia del Santo, Bendito Sea, encontrareis su humildad». ${ }^{[16]}$ Hecho que no reconocen los babelitas. Phillip Michael Sherman, en su exhaustiva revisión de los primeros comentadores de Babel, señala que la búsqueda de reconocimiento público a la que alude el pasaje en cuestión muy posiblemente se refiera a la fama de los nephilim, híbridos humano-celestiales, conocidos en la Antigüedad como héroes u hombres del nombre y surgidos de una problemática confusión entre lo divino y lo humano (Génesis 6:1-4). ${ }^{[17]}$ Por su parte, Pseudo-Filón cuenta que la arrogancia de los arquitectos de Babel era tal que inscribían sus propios nombres en los ladrillos de la torre. Solo un puñado de hombres se habría negado a llevar a cabo tal blasfemia, entre ellos, Abram. ${ }^{[18]}$ La enormidad de este gesto prepotente se entiende más claramente si recordamos que, en el pensamiento mesopotámico, la iniciativa de construir ciudades es divina, por ejemplo, Marduk proyectando la fama de su Esagila en el Enuma Elish. Al plasmar su nombre en cada ladrillo, los constructores hacen suya una prerrogativa reservada a los dioses. De ahí la crítica tajante del autor yahvista, que, al emplear el cronotopo de Babel, situado entre el mito y la historia, refuerza esta idea del comportamiento idolátrico de los constructores de ciudades. «Babel es Babilonia, pero el cronotopo se presente a aquí con un aura de misterio para incluir a todas las "Babel" de la historia humana». ${ }^{[19]}$ Su emplazamiento mismo es ya muy significativo. LaCocque nos remite a un pasaje de Daniel $(1: 2)$ en el que Shinar, el valle donde se establecen los hombres de Babel, es referido como 
el lugar del tesoro de los dioses de Nabucodonosor. En esta penumbra de lo sagrado, ese «reverso de lo real» ${ }^{[20]}$ rechazado por la revelación, idolatría y prestigio irían así de la mano. Por su parte, el Targum, traducción aramea de la Torá, en una paráfrasis del versículo 11:4 que habla de la cúspide de la torre, nos dice que en ella había «un ídolo armado en la cima para combatir a Dios». ${ }^{[21]}$ Hacerse de un nombre equivale entonces a erigir un ídolo. Y si detrás del prestigio está la hazaña guerrera, ¿se encuentra entonces Babel en un estado de excepción, se prepara para una guerra?

En sus Antigüedades bíblicas, al enumerar a los descendientes de Noé -genealogía que en la Biblia precede inmediatamente al relato de Babel-, Pseudo-Filón nos ofrece el espectáculo de numerosas huestes cuya formación sugiere que están armadas hasta los dientes. ${ }^{[22]}$ Sufriendo entonces de una fascinación irresistible por el centro que reúne en sí todas las direcciones, los hombres de Babel prefieren ahorrarse la belicosidad de la dispersión y optan por concentrarse bajo la tiranía de un proyecto y una lengua instrumental. Este gesto preventivo explica, de alguna manera, todas las tiranías. Catherine Chalier, destacada discípula de Levinas, lo describe así: «La tiranía, pública o privada, prohíbe que rostros y nombres emerjan [...]. La persecusión que ejerce el tirano corresponde al deseo de mantener a cada cual [...] en el dolor, a veces desconocido para sí, de la indistinción entre uno mismo y el otro».[23] Tendríamos entonces, como una de las principales consignas de los constructores, una búsqueda de uniformidad que ominosamente recuerda la indiferenciación que Girard detecta tras la formación de ídolos. Y si esta tiene en su origen la exacerbación de las rivalidades miméticas, tenemos aquí también fuertes indicios de una situación tal. El historiador y general que era Flavio Josefo nos ofrece tanto un contexto existencial que en el texto bíblico no es explícito -tras el diluvio los hombres sufren de una profunda angustia- como una exhortación divina que recomienda a los hombres el establecimiento en colonias lejanas a Shinar para evitar el conflicto que una concentración tal de personas propiciaría. Pero los hombres desobedecen porque se insinúa entre ellos la posibilidad de una conspiración divina que los haría más susceptibles a la invasión. [24] Se desliza aquí entonces la sospecha de un celo divino, phtonos, que en el fondo es pura animosidad humana, dinámica que según Girard echa a andar la catástrofe del relato adámico. ${ }^{[25]}$ Aprovechando, además, las genealogías que sitúan a Nimrod en Shinar, habla este autor incluso de una venganza contra Dios proyectada por los hombres y liderada por este temible cazador que pretende «liberar a los hombres de su temor de Dios aterrorizándolos con la idea» de un eventual cataclismo de origen divino..[26] Como señala acertadamente Girard, una vez instalados en el seno de la violencia sagrada, la lógica que pretende desafiarla solo consigue perpetuarla. Y si bien el pasaje del Génesis habla de un acuerdo entre todos, Flavio Josefo nos presenta una figura carismática, Nimrod, que «está sintonizada con los deseos del pueblo. Como un espejo, devuelve a la gente la imagen de su propia estima y supuesta virtud [...] única causa [admisible] de su prosperidad».[27] Los hombres de Babel estarían presos del mismo discurso, analizado por Girard, que esgrimen los amigos de Job, que estiman altamente su propia virtud y se complacen en la caída de los poderosos cuando dejan de satisfacerlos. Estos presuntos amigos, igual que nosotros, se niegan a ver cómo los líderes solo son tales cuando cumplen ese reflejo de los deseos del colectivo. El soberano, así, funciona exactamente como un ídolo: su condición reflectante determina la jerarquía de los existentes, desde la mirada que lo postula al desearlo y de vuelta. $^{[28]}$ Su decisión es, al fin y al cabo, la del pueblo y sus ansias de prestigio. A propósito 
de la ontología fundamental como filosofía del poder, Levinas habla en Totalidad e infinito de esos estados del alma paganos gracias a los cuales los hombres pueden profesar por sus amos incluso adoración. ${ }^{[29]}$ Tanto el pasaje de Josefo, a propósito de Babel, como el Libro de Job, en la interpretación de Girard, mostrarían cómo el famoso dictum vox populi, vox dei implica siempre una usurpación. ${ }^{[30]}$ La torre, entonces, como vector de fuerzas, ocultaría así un auténtico universo totalitario: «Cuando uno plantea las libertades las unas al lado de las otras como fuerzas que se afirman y se niegan recíprocamente uno desemboca en la guerra en las que limitan las unas a las otras. Ellas se impugnan o se ignoran inevitablemente, es decir, no ejercen más que violencia y tiranía».[11]

Cuenta André Neher que, según los doctores del Talmud, cada vez que se rompía un ladrillo en Babel, las obras se detenían, los hombres se rasgaban las vestiduras y las mujeres se hundían en terribles lamentaciones y que, en cambio, cada vez que un constructor moría, la jornada se completaba sin más. Recordemos que en esos ladrillos cada uno escribía su nombre dejando a merced del monumento su única posteridad: su fascinación por lo irrompible. La de Babel sería entonces una existencia exclusivamente administrativa: la cosa y la palabra -olvidado el antiguo significado de dabar como 'promesa, enunciación, ocupación, acto'-[32] se hacían una, debarim'ahadim, gracias a una alquimia de fines económicos y circuitos cerrados. La versión de Babel contenida en el texto apócrifo 3 Baruch afirma que el ritmo de producción no se detenía ni para las parturientas. ${ }^{[33]}$ Y si, como señala Levinas, el sabath como mandamiento y realidad ontológica de la menunah representa una novedad, una auténtica aportación hebrea al pensamiento y a la labor sin pausa de los pueblos arcaicos, está claro que los hombres de Babel desafían a Dios incluso en esos términos. En palabras de Abraham Heschel:

"Menunah» que generalmente traducimos como "descanso" significa aquí mucho más que el abandono de las labores y del esfuerzo, mucho más que libertad del trasiego o de la actividad de cualquier tipo. «Menunah» no es un concepto negativo sino algo real eintrínsecamente positivo. Esta debió ser la opinión de los antiguos rabinos si creían que se necesitó un acto especial de la creación para traerla al ser y que el universo estaría incompleto sin ella [...] la paz. ${ }^{[34]}$

En este universo concentracionario, obsesionado con la edificación, los objetos, insiste Neher, hablaban entonces por la humanidad, en lugar de la humanidad, y, como lo señala su colega Abraham Heschel, «cuando el hombre se vende a sí mismo como esclavo de las cosas, se convierte en un utensilio que se rompe en la fuente". ${ }^{[35]}$ Pseudo-Filón, en esta misma línea de denuncia, tan clara en el redactor yahvista, nos dice que la referencia a los ladrillos funciona en la Biblia no como una mera crítica a los sistemas constructivos extranjeros -los hebreos edificaban en piedra-, sino que es un código, un leitmotiv, que nos refiere a una opresión paradigmática, como sucede en Éxodo 5:6-9. ${ }^{[36]}$ Reitera Neher:

Nos parece que el halo sentimental con el que el midrás envuelve el episodio tipo ha de permitir evocar la tragedia de la dimisión del hombre ante el artificio. El trabajo silencioso y eficaz del ladrillo y la presencia inmóvil de la 
obra de arte en las dimensiones de su tiempo y de su espacio ejercen sobre el hombre una especie de tentación, invitándolo a hacerse semejantes a esa cosa, de armonías perfectas y aparentemente indestructibles. ${ }^{[37]}$

«Nada de cuanto se propongan les será imposible». ¿Condena Dios toda iniciativa humana o tan solo un proyecto que tiene en su origen la consolidación de un nombre que se quiere único, que actúa, como dice Levinas, a propósito de la violencia, como si no hubiera nadie más en la tierra? La torre, tras la intervención divina, no es derribada, solo queda incompleta. No es, pues, Babel el relato de una masacre. Solo la mala voluntad de una mímesis negativa, como demuestra Girard, haría surgir la noción de una trascendencia punitiva a partir del mal que infligimos a nuestras víctimas; y víctimas, según los doctores del Talmud, en Babel había muchas. Dios se presenta, entonces, no para fulminar a los titanes tras un terrible crimen, no para atar a Prometeo y garantizar su soberanía usurpada, sino para, interrumpiendo una ocupación tan prosaica como blasfema, hacerles ver a los hombres la iniquidad de su búsqueda fanática del prestigio mundano. Este, como sostiene Girard, supone siempre una rivalidad y un afán de dominio que, si bien quedan ocultos en los mitos, en la escritura son denunciados desde sus primeros capítulos. Tenemos en Babel, pues, todos los elementos para una tragedia; no obstante, nos dice Flavio Josefo, porque «no estaban en sus cabales», Dios decide no exterminar a los arrogantes constructures. Y este estar fuera de sí del que Dios se compadece es justamente la ignorancia negligente o méconnaisance de la que se encuentra presa la humanidad mítica según Girard. Este sería, en efecto, el sino de una humanidad caída, «porque las formas del corazón humano son malas desde su juventud», como reza el Génesis 8:21. Levinas reconoce también la «inconsciencia» del paganismo, de la humanidad «bosque» que no tiene nada de pacífica. ${ }^{[38]}$ Así, a contracorriente de lo temido por los hombres asentados en Shinar, Dios conmuta la condena y reabre la dimensión del tiempo para una generación obsesionada con el axis mundi del espacio urbano.

El pensamiento bíblico sustituye a esa humanidad anodina, que servía de pedestal a las conquistas metafísicas en el simbolismo del zigurat, a esa individualidad aislada y cercada sobre sí misma de Prometeo, por la comunidad de pueblos, que habla cada uno su propia lengua [...] desempeñando cada uno un papel concreto e irreductible en la historia [...]. El dominio de los espacios terrenos y cósmicos no puede alcanzarse por la conquista, sino por el tiempo. ${ }^{[39]}$

Se trata aquí de un tiempo abierto, mesiánico, no un tiempo utópico siempre asintóticamente pospuesto. La crítica a este último, nos dice Stéphan Moses, ${ }^{[40]}$ queda perfectamente ilustrada por el cuento de Kafka El escudo de la ciudad, su propia versión del episodio de Babel. En este relato, los hombres de esta villa, obsesionados con la perfección posible de la torre, aplazan la construcción de esta hasta tener los medios tecnológicos que garanticen dicha plenitud. Paradójicamente, estos aplazamientos, en lugar de hacer correr el tiempo, lo liquidan, porque el futuro en nada compromete a la generación de Babel una vez que la idea tectónica ha sido concebida. El «mito del mito», que es Babel según Derrida, denuncia así el 
gesto ególatra y de clausura de los hombres fascinados por el proyecto de la torre y sumidos en una obsesión mítica: la amenaza de un puño que lo destruiría todo al final se muestra como ese asedio de la violencia sagrada, a la que también temen los hombres de los que habla el Génesis cuando se previenen de la dispersión y que marca a la mentalidad arcaica. De ahí que busquen un refugio contra la historia, contra el diálogo cuya condición es mantenerse inerme frente al otro. Nos dice Lévinas en este respecto:

La Historia [...] resulta no del pecado, sino de la creación del hombre. La verdadera paradoja del ser perfecto consistió en querer crear pares por fuera de él, una multiplicidad de seres, y por consiguiente, una acción más allá de la interioridad. Es allí donde Dios trascendió la creación misma. Es allí donde Dios «se vació». Creó alguien con quien hablar. ${ }^{[41]}$

LaCocque llega incluso a equiparar, aunque solo de paso, el descenso de Dios en Babel también con una kenosis o vaciamiento, y no podemos atribuir a este autor más que una plena conciencia de las graves consecuencias teológicas de una afirmación tal. ${ }^{[42]}$ Pero justamente, si el episodio de Babel trata de la reinauguración de la historia y de la reapertura de un diálogo tras la inauguración fallida de las ciudades fundadas siguiendo el modelo de la erigida por Caín, y si el arranque de esta historia está marcado, como sostiene Levinas, por ese gesto de humildad de Dios, entonces, cada vez que se reabre el tiempo, Dios reitera ese desasimiento. Esta deposición de un yo monolingüe fascinado por las potencias de lo mismo -tema levinasiano donde los haya- también evoca para Derrida la separación con respecto de sí que Dios lleva a cabo cuando permite la famosa rotura de los vasos: gesto silencioso de la divinidad, que no castiga implacablemente, sino que nos permite hablar haciendo de la traducción su ley. ${ }^{[43]}$ Ley que, en el texto que Derrida dedica a Babel, deja su impronta en el nombre mismo de la ciudad en adelante abandonada. Si la primera llevaba el nombre del hijo de Caín, esta Shinar llevaría el nombre de Dios, Confusión, según este autor. En esta misma línea, el texto derrideano menciona casi desde el comienzo la extrañeza que el nombre de la ciudad, que como muchas de la Antigüedad es bautizada con el nombre de Dios, despierta en Voltaire:[44] ¿Por qué el patronímico que instaura una comunidad apuesta más bien por su dispersión? Las razones ya las adelantó Flavio Josefo y, si retomamos la sugerencia derridiana, diríamos que en este pasaje Dios no se muestra como artífice, reproche heideggeriano repetido hasta el cansancio, sino como agente que erosiona toda tectónica; como agente, pues, de una deconstrucción.

Por eso Babel marcaría el cierre auténtico del relato de la creación, aún incompleta sin la multiplicidad linguística: «Dios ejecuta aquí algo que pertenece a la creación y en este sentido el relato de Babel concluye su narración». ${ }^{\left[{ }^{[5]}\right]}$ La uniformidad centrípeta arcaica se convierte así en una diversidad centrífuga obligada a la escucha y la traducción. Y, urbanitas que somos, a nuestro pesar nos adentramos, después de Babel, en un tiempo que no se transmutaría ya en un gran relato que, a la manera de la mitología, legitima todo cuanto sucede en su seno instrumental, tal y como acontecía en la famosa ciudad y en su torre. Sobre esta irrupción y su retirada, descenso y elevación de Dios que, no obstante, siempre queda a merced de la iniciativa humana, nos dice Levinas: «Quizá Dios no sea sino este permanente negarse a una historia que se las compone perfectamente con nuestras lágrimas privadas». ${ }^{[46]}$ 


\section{NotAs}

[1] Cfr. Brueggemann, W. (1982). Genesis. Interpretation. Westmister John Know, Louisville. Aunque ambos autores se citan y se admiran, LaCocque no concuerda con Brueggeman en una reivindicación cainita o incluso babélica a expensas de Dios.

[2] LaCocque, A. (2010). The Captivity of Innocence. Eugene, Estados Unidos: Cascade Books, p. 13. [3] Cfr. Ricoeur, P. (1986). «El mito adámico y la visión escatológica de la historia». En Finitud y culpabilidad (cap. III). Madrid, España: Taurus.

[4] Según las proyecciones del Banco Mundial, de la población total del mundo, el 68 \% será urbana para el 2050.

[5] Génesis, 4:17-24.

[6] Los tres tomos de las Fundaciones de Serrés constituyen un proyecto de corte girardiano, como el propio Serrés lo reconoce en la dedicatoria del primer volumen, que constituye una lectura minuciosa de Tito Livio.

[7] Michel Serrés (2015). Rome: the First Book of Foundations. Nueva York, Estados Unidos: Bloomsbury Academic, p. 54.

[8] Cfr. Dupuy, J.-P. (2013). The Mark of the Sacred. Stanford University Press, p. 175.

[9] Filón. De Opificio Mundi. 49142. Citado por LaCocque (2008). Onslaught against innocence. Eugene, Estados Unidos: Cascade Books, p. 126.

[10] LaCocque. Onslaught against innocence. P. 126.

[11] Levinas, E. Difícil Libertad. Buenos Aires, Argentina: Lilmod, p. 152.

[12] LaCocque. Captivity of Innocence, p. 26.

[13] LaCocque, lo mismo que Derrida en Des tours de Babel (Galilée [1998]. Psyché. Inventions de l'autre. París, Francia, pp. 203, 236), sigue la traducción de André Chouraqui. En línea se puede consultar en: http://nachouraqui.tripod.com/id83.htm Para una lectura de corte levinasiano que se complementa con la interpretación derridiana, cfr. Checchi González, T. (2007). «De Babely el Sinaí: en torno a la ley, la traducción y la escucha». En Revista de Filosofía, n.․120, Universidad Iberoamericana, México, pp. 87-104.

[14] Cfr. Auerbach, E. (2003). Mimesis. The Representation of Reality in Western Literature. Princeton University Press, p. 22. A diferencia de la poesía homérica en la que lo doméstico prácticamente no tiene cabida y la hierofanía se restringe al campo de batalla donde solo la aristocracia destaca, en el Antiguo Testamento, señala Auerbach, la influencia de Dios llega tan hondamente a la vida de los hombres que la diferencia entre lo sublime y lo cotidiano queda borrada.

[15] LaCocque, A. The captivity of innocence. P. 27.

[16] Levinas, E. (1988). «Kenosis et judaisme». A l'heure des nations. París, Francia: Les éditions de minuit, p. 134.

[17] Cfr. Sherman, P. M. (2013). Babel's Tower Translated. Genesis 11 and Ancient Jewish Interpretation. Biblical Interpretation Series. Boston, Estados Unidos: Leiden, p. 51.

[18] Sherman. Op. cit., p. 131.

[19] LaCocque. Captivity of Innocence. P. 43.

[20] Levinas, E. (1997). De lo sagrado a lo santo. Cinco lecturas talmúdicas. Barcelona, España, p. 92.

[21] Citado por LaCocque en Captivity of Innocence, p. 50. 
[22] Pseudo-Philo (2013). Biblical Antiquities of Philo. HardPress Publishing, p. 87-89.

[23] Chalier, C. (2002). Para una moral más allá del saber. Madrid, España: Caparrós, p. 103.

[24] Flavio Josefo. Antigüedades judías (párrafo 112).

[25] Cfr. la prolongación que de este análisis Ileva a cabo Oughourlian, J. M. (2010). The Genesis of Desire. Michigan State University, pp. 43-54.

[26] Sherman. Babel's Tower Translated. P. 171.

[27] Sherman. Op. cit., p. 179. El paréntesis es nuestro y completa el sentido del párrafo en el que se encuentra inserta esta frase.

[28] Cfr. Marion, J. L. (1991). God without Being. University of Chicago Press, pp. 9-14.

[29] Levinas (2013). Totalidad e infitino. Salamanca, España: Ediciones Sígueme, p. 43.

[30] Cfr. Girard, R. (1999). La ruta antigua de los hombres perversos. Barcelona, España: Anagrama, pp. 20-25 y 104.

[31] Levinas (1994). Liberté et Commendement. París, Francia: Fata Morgana, p. 146.

[32] Heschel, A. (2005). «The architecture of time». En The Sabbath. Farrar Strauss Giroux, p. 7.

[33] Cfr. 3 Baruch 2-3 citado en Sherman, P. M. Op. cit., p. 201.

[34] Heschel, A. J. (1997). Between God and Man. An Interpretation of Judaism. Free Press Paperbacks, p. 220.

[35] Heschel, A. Op. cit., p. 4.

[36] Sherman, M. P. Babel's Tower Translated. P. 59.

[37] Neher, A. (1997). El exilio de la palabra. Barcelona, España: Ríopiedras, p. 107.

[38] Levinas, E. «Simone Weil contra la Biblia». DL, p. 155.

[39] André Neher (1974). La esencia del profetismo. Salamanca, España: Ediciones Sígueme, p. 127. [40] Cfr. Moses, S. (1997). El ángel de la historia. Madrid, España: Cátedra, pp. 11-25.

[41] Levinas, E. Difícil libertad. P. 156.

[42] Si bien Levinas cita numerosos ejemplos veterotestamentarios y talmúdicos para ilustrar la noción de kenosis en la tradición judía, en la cristiana, la referencia absoluta para esta idea es la epístola paulina Filipenses 2:6,11.

[43] «Dios se ha separado de sí para dejarnos hablar, para que nos extrañemos y nos preguntemos». Derrida, J. (1997). Escritura y diferencia. Barcelona, España: Anthropos, p. 94. Cfr. También Derrida, J. (1997). El monolingüismo del otro. Buenos Aires, Argentina: Ediciones Manantial, pp. 35-42.

[44] La entrada sobre Babel y Babilonia escrita por Voltaire para el Diccionario filosófico se puede consultar en línea en https://www.e-torredebabel.com/Biblioteca/Voltaire/Babel-Diccionario-Filosofico.htm

[45] Van Wolde, E. (1994). «The Tower of Babel as Lookout over Genesis 11:1-9». En Worlds become Worlds: Semantic Studies of Genesis 1-11. Biblical Interpretation Series 6. Leiden Brill, 1994, p. 103. [46] Levinas, E. Cuatro lecturas talmúdicas. P. 39. 